\title{
PENETRATING TRAUMA OF BRACHIOCEPHALIC ARTERY LESION WITH EMBOLIZATION OF FOREIGN BODY TO RIGHT AXILLARY ARTERY IN PEDIATRIC PATIENT: CASE PRESENTATION AND HIS MANAGEMENT.
}

Luis Zerpa Acosta ${ }^{1}$, Jameel Al Ata ${ }^{1}$, Alfredo Sanchez Gamboa ${ }^{1}$, Elmahi Babikir ${ }^{1}$, Abdullah Al Zahrani ${ }^{1}$, Francis Emperador ${ }^{1}$, and Ali Haneef ${ }^{1}$

${ }^{1}$ King Abdulaziz Medical City - Jeddah

November 21, 2020

\begin{abstract}
ABSTRACT: BACKGROUND: Penetrating injuries of the intrathoracic great vessels are well recognized although uncommon in pediatric patients, management in pediatric patients presents challenges. Surgical repair by median sternotomy is the exposure of choice for accessing innominate artery injuries, but endovascular intervention in being increasingly introduced in the hemodynamically stable
\end{abstract}

\section{Hosted file}

PENETRATING TRAUMA OF BRACHIOCEPHALIC ARTERY LESION WITH EMBOLIZATION OF FOREIGN BODY TO RIGHT AXILLARY

available at https://authorea.com/users/360908/articles/494248-penetrating-trauma-ofbrachiocephalic-artery-lesion-with-embolization-of-foreign-body-to-right-axillaryartery-in-pediatric-patient-case-presentation-and-his-management 


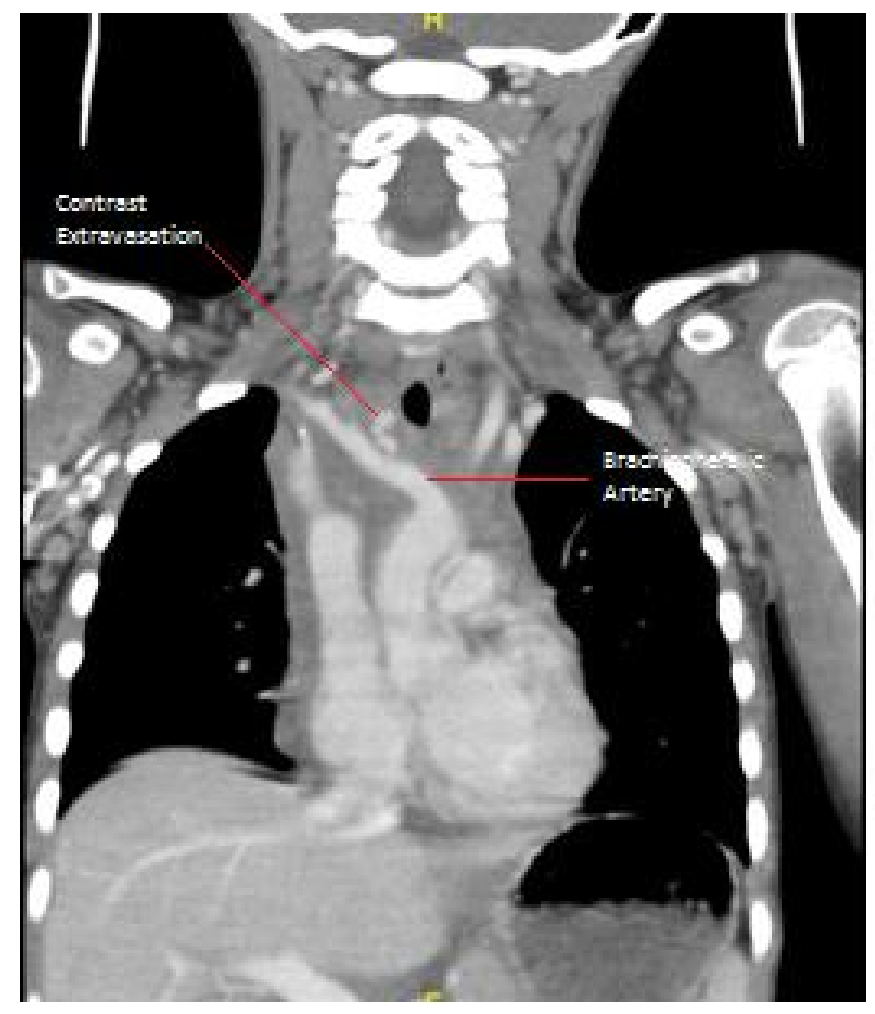




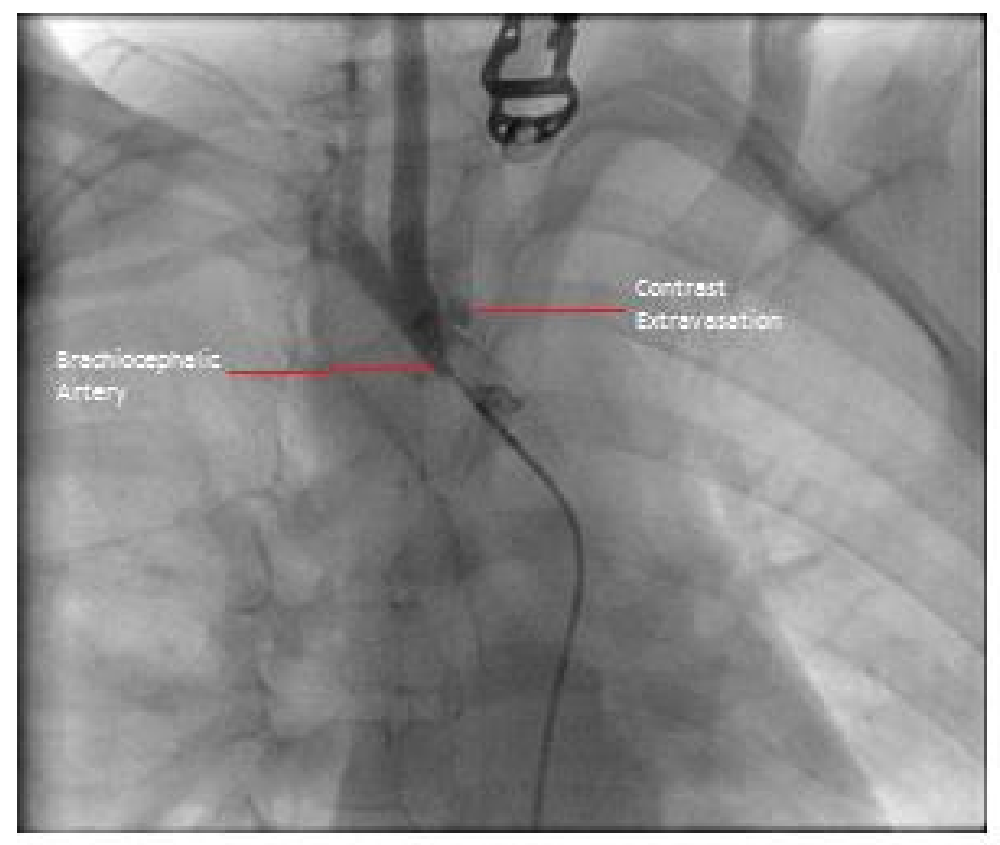




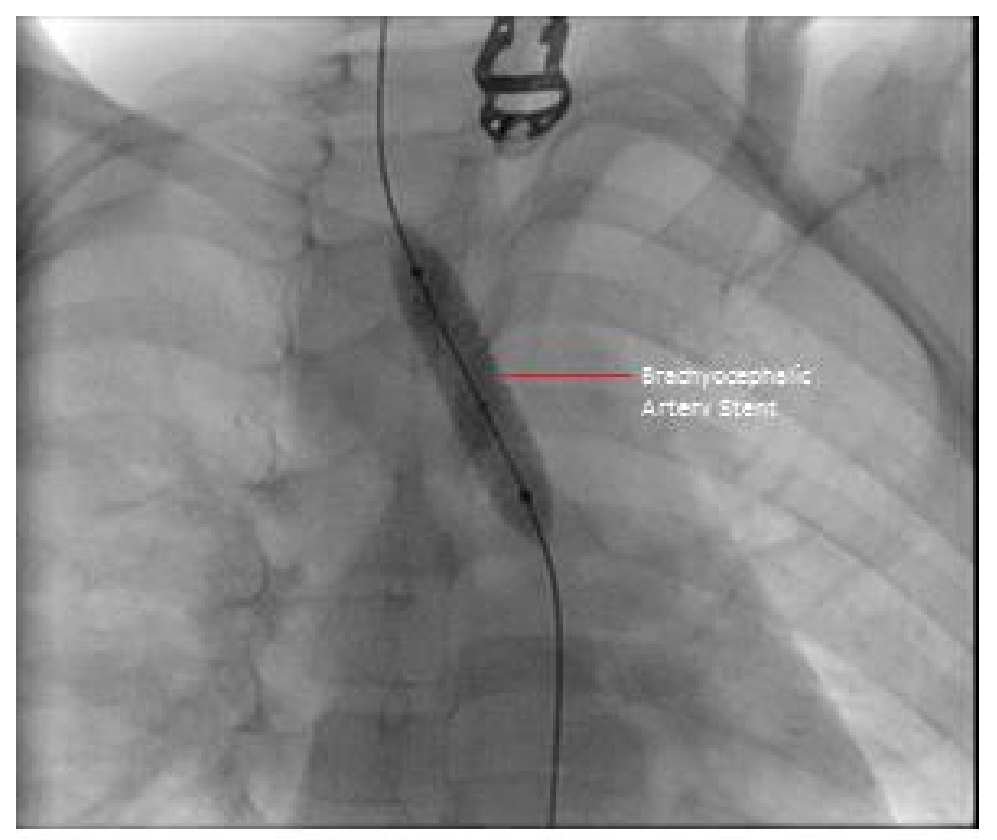




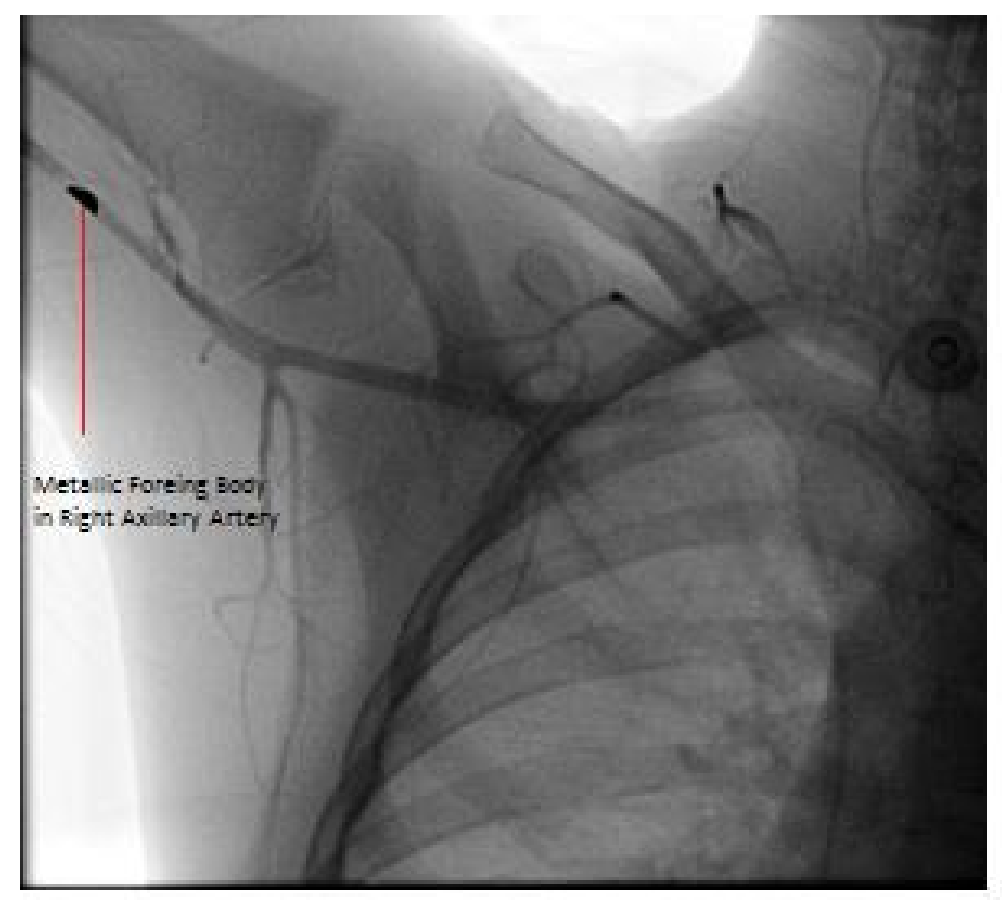

